\title{
Emergency Department Triage Decisions: Personnel and Parameters
}

\author{
Acil Servis Departmanı Triyaj Kararları: Sağlık Çalışanları ve Parametreler
}

\author{
(D) Onur Polat ${ }^{1}$, (1) Ayça Koca Tanrıverdi ${ }^{2}$, (D) Müge Günalp Eneyli ${ }^{1}$, (1) Serdar Gürler ${ }^{1}$, (1) Sinan Genç ${ }^{1}$, (1) Ahmet Burak Oğuz ${ }^{1}$, \\ (D) Atilla Halil Elhan ${ }^{3}$ \\ ${ }^{1}$ Ankara University Faculty of Medicine, Department of Emergency Medicine, Ankara, Turkey \\ ${ }^{2}$ Ankara Yıldırım Beyazıt University, Yenimahalle Training and Research Hospital, Clinic of Emergency Medicine, Ankara, Turkey \\ ${ }^{3}$ Ankara University Faculty of Medicine, Department of Biostatistics, Ankara, Turkey
}

\section{Abstract}

Objectives: Triage aims to determine the clinical priority of patients based on their presenting features. Scoring systems-including physiological parameters-to predict mortality have been described, but in most triage methods used in emergency departments, vital signs or laboratory parameters are not included as standard assessments. The objective of this study was to measure agreement and acuity on the urgency of an emergency department patient between the points of views of healthcare professionals. We also sought to determine which vital signs and parameters affect triage decision by creating several mods with different parameters.

Materials and Methods: This prospective study was carried out on 550 patients referred to an academic emergency department. The patients triage levels were determined by nurses, intern doctors, residents and emergency physicians. Eleven mods were defined with several components, for each mod 50 patients were selected. To evaluate the agreement between raters triage decisions, the chance-adjusted measure of agreement kappa was calculated.

Results: Of the 550 patients included in the study, agreement for nurses was 0.374 , kappa value between interns and physician was 0.257 , and a value of 0.311 was found for residents.

Conclusion: In emergency medicine, there is a strong need for sensitive tools to identify and characterize patients at admission to the emergency department. According to our results, the most important parameters affecting triage decision were found to be oxygen saturation and Glasgow Coma scale.

Key Words: Agreement, Emergency Department, Reliability Triage, Vital Signs

\section{Öz}

Amaç: Triyaj acil tıbbi bakımı bekleyebilecek olanlar ile bekleyemeyecek olanların ayrılması için yapılan uygulamadır. Mortaliteyi öngörmek için fizyolojik parametreler de dahil olmak üzere skorlama sistemleri tanımlanmıştır, ancak acil servislerde kullanılan çoğu triyaj yönteminde, vital bulgular veya laboratuvar parametreler standart değerlendirmeler olarak dahil edilmemiştir. Bu çalışmanın amacı, acil servise başvuran hastaların triyaj kararını farklı sağlık çalışanları arasındaki uyuşmalarını ölçmektir. Ayrıca, farklı parametrelerle modlar oluşturarak hangi vital bulguların ve parametrelerin triyaj kararını etkilediğini belirlemeyi amaçladık.

Gereç ve Yöntem: Bu prospektif çalışma, bir akademik acil servise başvuran 550 hasta üzerinde gerçekleştirildi. Hastaların triyaj düzeyleri hemşireler, stajyer doktorlar, asistanlar ve acil tıp uzmanları tarafından belirlendi. Farklı parametreler içeren 11 mod belirlenmiştir ve her mod için 50 hasta tanımlanmıştır. Uygulayıcıların triyaj kararları arasındaki anlaşmayı değerlendirmek için, kappa uyumluluk testi kullanılmıştır.

Bulgular: Çalışmaya dahil edilen 550 hasta için, kappa uyumluluk değeri hemşireler için 0,374, intörn doktorların; 257, asistanlar için 0,311 bulunmuştur.

Sonuç: Acil tıpta, acil servise kabul edilen hastaları tanımlamak için hassas araçlara güçlü bir ihtiyaç vardır. Sonuçlarımıza göre triyaj kararını etkileyen en önemli parametreler oksijen satürasyonu ve Glasgow Koma skalası olduğu tespit edilmiştir.

Anahtar Kelimeler: Uyumluluk, Acil Servis, Güvenilir Triyaj, Vital Bulgular

Address for Correspondence/Yazışma Adresi: Ayça Koca Tanrıverdi MD,

Ankara Yıldırım Beyazıt University, Yenimahalle Training and Research Hospital, Clinic of Emergency Medicine, Ankara, Turkey

Phone: +90 5413261465 E-mail: aycakoca@ hotmail.com ORCID ID: orcid.org/0000-0002-1546-3150

Received/Geliş Tarihi: 16.05.2018 Accepted/Kabul Tarihi: 01.06.2018

๑Copyright 2018 Ankara University Faculty of Medicine

Journal of Ankara University Faculty of Medicine is published by Galenos Publishing House.

All content are under CC BY-NC-ND license. 


\section{Introduction}

Triage is a way to determine medical priorities of patients using different decision making process at admission in an emergency department (ED). An adapted triage system has to assure that all patients requiring emergency evaluation are identified according to their clinical condition. It has been described as the sorting of medical conditions into different categories to achieve a true priority of care. Standard triage scales have been developed but a universal accurate interpretation has not yet been established. The Manchester Triage system, the Canadian Triage and Acuity scale and the Emergency Severity index, and the Australian Triage scales are the most commonly used triage systems in EDs (1). The Emergency Nurse Association triage manual describes several triage systems including 3-, 4-, and 5-level systems (2). In Turkey, in 2009, the Ministry of Health mandated a three-level emergency triage scale coded with the colours red, yellow and green in descending order of acuity (3). It has been noticed that there is little agreement on triage protocols despite its widespread use. A valid and reliable triage instrument would serve precious values like health care resources, fairness in distributions and values of human life (4). Triage acuity rating systems have been based solely on the acuity of the patient, determined through the nurse's assessment of vital signs, subjective and objective information, past medical history, allergies, and medications. Such systems require the nurse to assign an acuity level by making a judgment about how sick the patient is and how long the patient can wait to be seen by a provider. ED patient triage is a complex interaction between two persons in which verbal information (the patient history), visual cues (nonverbal communication), physical findings (limited physical examination), and vital signs all inform the decision making process. Each component likely plays an important part in accurate triage, with the relative importance of each element varying on a case-by-case basis. Vital signs have been reported to be of importance in triage decisions. For certain individuals, a triage process that does not account for these parameters may fail to recognize the actual urgency of the patient's presentation (5). In an ideal situation it is expected that if different people perform triage on same patients with same triage system, they would arrive at the same triage category. But the situation is not always like this and sometimes there seems disagreement about the triage category of the patient (6). The objective of this study was to measure agreement and acuity on the urgency of an ED patient between the points of views of triage nurses, ED residents, intern doctors (last year medical students), and ED physicians by using several parameters. Second, we sought to determine which vital parameters affect triage decision by creating several mods with different parameters and measure the duration of triage decision for each rater.

\section{Materials and Methods}

This study was conducted prospectively in an academic ED, which is a tertiary medical center ED in Turkey. This study was approved by the Ankara University Faculty of Medicine Ethics Committee (approval number: 13-629-16). A total of 550 patients were enrolled, patients were chosen in different hours of the day for varied complaints. Patients who were 17 years of age or younger were excluded from the study due to the different emergency criteria for pediatric patients. Triage categories were determined by triage nurses, intern doctors (last year medical students), senior ED residents and three attending emergency physicians. Emergency attending physicians were all five-year experts, triage nurses had at least two years of experience in the $E D$, all residents were at least in their third year of residency, and only intern doctors had no experience of the ED. In order to improve uniformity, all raters attended 16 hours training lectures in which triage and its categories and also basic life support and trauma life support were defined.

Eleven mods were defined with several components, for each mod 50 patients were selected, the mods contents were as followed.

Mod 1: vital signs (temperature, pulse, blood pressure, respiratory rate)

Mod 2: vital signs + Glasgow Coma scale (GCS)

Mod 3: vital signs + blood sugar

Mod 4: vital signs + pain

Mod 5: vital signs + oxygen saturation

Mod 6: vital signs + GCS + pain

Mod 7: vital signs + oxygen saturation + blood sugar

Mod 8: vital signs + blood sugar + GCS

Mod 9: vital signs + oxygen saturation + pain

Mod 10: vital signs + blood sugar + pain

Mod 11: vital signs + oxygen saturation + GCS

In order to assess urgency in a short period of time, and reduce triage decision disagreement, a three-level triage system was adopted accordingly to Content of the Ministry of Health of Turkey's emergency triage instrument (3). Triage categories were defined as follows:

Level 1: Emergent; patients assigned to triage level 1 required immediate medical attention with potentially life threatening conditions.

Level 2: Urgent; patients should receive attention within 30 minutes with no threat to life or limb. 
Level 3: Non-urgent; assignment to triage level 3 meant that the condition with which the patient present is non-urgent and medical care can be delayed.

A nurse in charge of vital signs required for each mod, had to register the values according to the mod chosen. The healthcare professional that had to decide final triage level of the patient saw the patient after the data were collected and registered.

In cases accepted level 1 of urgency, tests and necessary critical procedures were began because emergency of patient. During this study, there was no interruption in the normal order and functioning of the ED.

Each rater had to independently categorize patient's status according to determined components. The triage judgments made by emergency physicians were considered a gold standard. The time for triage decision of all raters was also measured except emergency physicians, because the 3 attending emergency physicians made a common decision on patient's triage level considering admission and outcomes. They saw the patients, and then were able to consider laboratory results and final diagnosis.

\section{Statistical Analysis}

Statistical analyses were conducted using SPSS for Windows Version 15.0 program. To evaluate the agreement between raters triage decisions, the chance-adjusted measure of agreement kappa (K) was calculated. Kappa is a measure that is frequently used in reliability studies. A kappa value of 0 represents the amount of agreement that can be expected from random chance, and 1 represents perfect agreement between the raters. Cohen suggested the Kappa result be interpreted as follows: values $\leq 0$ as indicating no agreement and $0.01-0.20$ as none to slight, $0.21-0.40$ as fair, $0.41-0.60$ as moderate, $0.61-0.80$ as substantial, and $0.81-1.00$ as almost perfect agreement (7).

\section{Results}

Triage data were collected for 550 patients. From the 550 patients, $43.5 \%(n=239)$ were male, $56.5 \%(n=311)$ were female.

The mean age of the 550 patients who were enrolled into the study was 49.9 (standard deviation \pm 20.149 ) years. The demographic characteristics of the study population are presented in Table 1. Our emergency physicians evaluations, considered as gold standard attributed level 1 to $30.7 \%$ of the patients, gave $23.5 \%$ a level 2 of triage and $45.8 \%$ were considered as non-urgent (level 3) (Table 2). Of the 550 patients included in the study, agreement for nurses was 0.374, kappa value between interns and physician was 0.257 , and a value of 0.311 was found for residents (Table 3 ).

When considering kappa value for each mod, we noticed that except for one mod, nurses-physician agreements were at least considered fair. Nurses' evalutions were observed to be moderate for 5 mods. The highest kappa value was found in mod 5, which contained vital signs and oxygen saturation.

Intern doctors had the lowest kappa value for overall patients, the highest value was observed in mod 11 with a moderate score of 0.405 , whereas in this mod, both nurses and residents had only a fair agreement with the physician.

Besides kappa between raters, generalized kappa was considered (Table 4). Among 4 raters, the highest level of agreement was found using mods 5 and 6. Of 11 modes, we noticed a generalized kappa score higher than 0.4 in 5 mods

Table 1: Demographics of the study

\begin{tabular}{|c|c|c|c|c|c|}
\hline & \multicolumn{4}{|c|}{ Gender } & \multirow[t]{3}{*}{ Age (Mean) } \\
\hline & \multicolumn{2}{|c|}{ Female } & \multicolumn{2}{|c|}{ Male } & \\
\hline & n & $\%$ & n & $\%$ & \\
\hline Mod 1 & 31 & 62 & 19 & 38 & 39.52 \\
\hline Mod 2 & 32 & 64 & 18 & 36 & 51.04 \\
\hline Mod 3 & 32 & 64 & 18 & 36 & 54.24 \\
\hline Mod 4 & 27 & 54 & 23 & 46 & 45.72 \\
\hline Mod 5 & 24 & 48 & 26 & 52 & 52 \\
\hline Mod 6 & 30 & 60 & 20 & 40 & 51.78 \\
\hline Mod 7 & 25 & 50 & 25 & 50 & 53.36 \\
\hline Mod 8 & 26 & 52 & 24 & 48 & 54.82 \\
\hline Mod 9 & 28 & 56 & 22 & 44 & 42.98 \\
\hline Mod 10 & 33 & 66 & 17 & 34 & 52.6 \\
\hline Mod 11 & 23 & 46 & 27 & 54 & 51.66 \\
\hline Total & 311 & 56.5 & 239 & 43.5 & 49.97 \\
\hline
\end{tabular}

Table 2: Emergency physician decision: percentage of patients for each triage level and each mod

\begin{tabular}{|c|c|c|c|}
\hline \multirow[t]{2}{*}{ Mod } & \multicolumn{3}{|c|}{ Triage level } \\
\hline & 1 & 2 & 3 \\
\hline Mod 1 (VS) & 8 & 28 & 64 \\
\hline Mod 2 (VS+GCS) & 28 & 16 & 56 \\
\hline Mod 3 (VS+BS) & 42 & 22 & 36 \\
\hline Mod 4 (VS+pain) & 26 & 28 & 46 \\
\hline Mod 5 (VS+O ${ }_{2}$ sat) & 26 & 24 & 50 \\
\hline Mod 6 (VS+pain+GCS) & 28 & 20 & 52 \\
\hline Mod 7 (VS+O 2 sat+BS) & 38 & 18 & 44 \\
\hline Mod 8 (VS+BS+GCS) & 44 & 22 & 34 \\
\hline Mod 9 (VS+O 2 sat+pain) & 28 & 18 & 54 \\
\hline Mod 10 (VS+BS+pain) & 28 & 42 & 30 \\
\hline Mod 11 (VS+ $0_{2}$ sat+GCS) & 42 & 20 & 38 \\
\hline Total & 30.7 & 23.5 & 45.8 \\
\hline
\end{tabular}




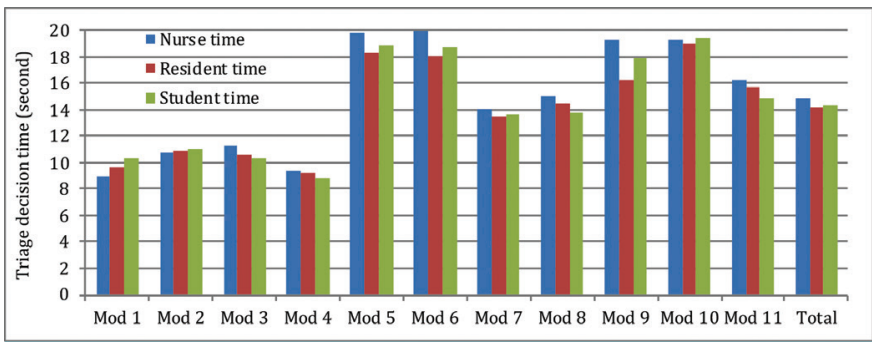

Figure 1: Triage decision time of raters for each mod

Table 3: Agreement between raters in each mod for different levels of triage

\begin{tabular}{|c|c|c|c|}
\hline & Nurses & $\begin{array}{l}\text { Intern } \\
\text { doctors }\end{array}$ & Residents \\
\hline Mod 1 (VS) & 0.131 & 0.089 & 0.246 \\
\hline Mod 2 (VS+GCS) & 0.420 & 0.258 & 0.452 \\
\hline Mod 3 (VS+BS) & 0.328 & 0.144 & 0.292 \\
\hline Mod 4 (VS+pain) & 0.274 & 0.343 & 0.209 \\
\hline Mod 5 (VS+O ${ }_{2}$ sat) & 0.558 & 0.311 & 0.444 \\
\hline Mod 6 (VS+pain+GCS) & 0.513 & 0.298 & 0.612 \\
\hline Mod 7 (VS+O 2 sat+BS) & 0.492 & 0.281 & 0.413 \\
\hline Mod 8 (VS+BS+GCS) & 0.333 & 0.252 & 0.136 \\
\hline Mod 9 (VS+O_sat+pain) & 0.415 & 0.179 & 0.179 \\
\hline Mod 10 (VS+BS+pain) & 0.204 & 0.097 & 0.138 \\
\hline Mod 11 (VS+O $\left.{ }_{2} \mathrm{sat}+\mathrm{GCS}\right)$ & 0.277 & 0.405 & 0.297 \\
\hline Total & 0.374 & 0.257 & 0.311 \\
\hline
\end{tabular}

VS: Vital signs (body temperature, pulse, blood pressure, respiratory rate), GCS: Glasgow Coma scale, BS: Blood sugar, 02sat: Oxygen saturation

Table 4: Generalized kappa results for all raters

\begin{tabular}{|c|c|}
\hline & $\begin{array}{l}\text { Generalized kappa } \\
\text { (4 raters) }\end{array}$ \\
\hline Mod 1 (VS) & 0.313 \\
\hline Mod 2 (VS+GCS) & 0.408 \\
\hline Mod 3 (VS+BS) & 0.266 \\
\hline Mod 4 (VS+pain) & 0.386 \\
\hline Mod 5 (VS+O ${ }_{2}$ sat) & 0.466 \\
\hline Mod 6 (VS+pain+GCS) & 0.458 \\
\hline Mod 7 (VS+O ${ }_{2}$ sat+BS) & 0.404 \\
\hline Mod 8 (VS+BS+GCS) & 0.327 \\
\hline Mod 9 (VS+O ${ }_{2}$ sat+pain) & 0.387 \\
\hline Mod 10 (VS+BS+pain) & 0.242 \\
\hline Mod 11 (VS+ $\left.\mathrm{O}_{2} \mathrm{sat}+\mathrm{GCS}\right)$ & 0.433 \\
\hline Total & 0.384 \\
\hline
\end{tabular}

(modes 2, 5, 6, 7, and 11). Mod 2 evaluated vital signs and GCS, mod 5 gave along with vital signs oxygen saturation, in mod 6, pain and GCS were registered, mod 7 contained oxygen saturation and blood sugar, and finally mod 11 components were oxygen saturation and GCS. The highest agreement was found in mode 5 with a score considered moderate of 0.466 .

In order to evaluate triage decision time, each rater's time to decision for a triage code was measured (Figure 1). According to our findings, except mod 9 there was no statistically significant difference between all raters. Mod 9 parameters were vital signs, oxygen saturation and pain, although triage nurses time decision was longer in this mod than residents and interns, their level of agreement was moderate whereas residents and interns gave a poor level of agreement in this mod.

\section{Discussion}

Triage is a complex decision-making process and several triage scales have been designed as decision-support system to guide correct decision. The triagists must be experienced with clinical features of patients presenting at the ED and well trained for the particular triage tool. Furthermore, the triage system must be to match the broad spectrum of patients visiting the ED.

Triage studies have stated important principles in the application of triage criteria. It remains essential that patients be assessed appropriately and assigned a triage acuity that accurately reflects their severity of illness so they receive safe and timely care (8).

Previously, scoring systems-including physiological parameters-to predict mortality have been described, but in most triage methods used in EDs, vital signs or laboratory parameters are not included as standard assessments. However, vital signs have been reported to be of importance and superior for predicting mortality and stratifying level of urgency (2, $9,10,11)$.

Our study shows a moderate level of agreement between triage nurses, intern doctors, residents and emergency physicians in decision to categorize patient's urgency. This finding corroborates with the results of previous studies of Durand et al. (6), Brillman et al. (12), and Caterino et al. (13).

Findings of a study conducted by Pourasghar showed that there is little agreement between the triage nurses and ED physicians on the triage category of the patients. Kappa, which was used as a measure for inter-rater reliability of triages performed by the ETS, was in the range of poor to moderate agreement.

To our literature investigation, our study is the first to compare triage agreement between different health care 
professionals with and without triage experience by conducting real-life settings.

Despite most of triage studies that are based on fictious cases rather than real-life settings, our study is a prospective one in which all raters have seen all patients (14). According to Farrohkinia's systematic review, most triage scales present insufficient scientific evidence for assessing inter-rater agreement (14).

Brillman et al. (12) found only moderate levels of nurse and physician agreement in the categorization of patients according to a 4-level scale of urgency and similar results for triage on presentation have been obtained for urgent versus non-urgent assignment (15).

This study shows that the level of inter-observer agreement was not uniform across all mods. According to the mod analyzed, agreement was not uniform. Parameters assigned in each mod affected the level of agreement between observers. It seemed that mods 5, 6 and 7 showed better harmony. Mod 5 gave oxygen saturation along with vital signs, in mod 6, pain and GCS were registered, and mod 7 contained oxygen saturation and blood sugar. According to our results, oxygen saturation and GCS were the components that gave better agreement with gold standard. Since the rapidity of assessment and the accuracy of the judgments are often critical for patient safety, triage decisions can mark a profound effect on the outcomes of patients admitted. Although a variety of triage methods are in use, internationally no consensus has been reached on the functions that should be measured. The accuracy of triage decisions is also contingent upon the nature and quality of the data obtained by the nurse to decide acuity (16).

With this study, we have been abled to distinguish different triage decisions considering combination of several parameters accompanied to vital signs. Mods 5 and 6 in which oxygen saturation, pain and GCS were considered seemed to be the parameters that resulted with better level of agreement between health care professionals. Knowing patient's oxygen saturation which is a non-invasive, easy to evaluate parameter revealed amelioration of agreement. In two studies which aimed to predict acute mortality after ED arrival, oxygen saturation was found to be one of the three variables, along with age and level of consciousness that best predict mortality during hospitalization $(10,17)$. According to Widgren and Jourak (11) study, a protocol that includes physiological parameters could be a sensitive tool to find those critically ill. This confirms that a standardized clinical triage including vital signs as a standard assessment and not only chief complaints in the triage decision, is of importance to increase the sensitivity to find those at medical risk on admission to the ED.
The benefits claimed for triage include a reduction in waiting times, especially for more urgent patients. In order to evaluate triage decision time, each rater's time to decision for a triage code was measured by the software. According to our findings, except mod 9 there was no statistically significant difference between all raters. Mod 9 parameters were vital signs, oxygen saturation and pain, although triage nurses time decision was longer in this mod than residents and interns, their level of agreement was moderate whereas residents and interns gave a poor level of agreement in this mod. We could conclude that nurses, interns, residents gave the triage decision in a same range of time.

Of our 550 patients, emergency physicians gave 169 patients level 1 of triage urgency, whereas nurses gave level 1 to only 78 , interns to 76 and residents to 59. However other studies show that nurses prefer to err on the side of safety and consistently give higher priorities than doctors (18), in our findings all raters tend to under-triage. If under-triage occurs, potentially seriously ill patients may be triaged as non-urgent, resulting in an increase risk of adverse outcomes for these patients. A decision that under-estimates a person's level of clinical urgency may impede time critical intervention. Despite all raters did undertriage, nurses were the least to do it.

\section{Conclusion}

In emergency msedicine, there is a strong need for sensitive tools to identify and characterize patients at admission to the ED. Therefore, it is important that ED triage and management be more standardized to minimize the inter-rater disagreement, since vital signs and assessment of important physiological parameters are of major importance in all adult patients admitted to the ED.

The findings in our study suggest that anyone who decides on triage level will need a decision support system. This will increase accuracy and quality and will shorten the duration of triage decision; further investigations should be done in this regard. Our study shows that the nurses were able to give as accurate and quick triage decision as the doctors, and the most important parameters in triage decision are oxygen saturation and GCS. Stronger scientific evidence is needed to determine which of the vital signs have the greatest prognostic value in triage.

\section{Ethics}

Ethics Committee Approval: This study was approved by the Ankara University Faculty of Medicine Ethics Committee (approval number: 13-629-16).

Informed Consent: Written informed consent form was signed by all participants for our study. 


\section{Authorship Contributions}

Concept: O.P., A.K.T., M.G.E., S.G., A.B.O., A.H.E., S.G., Design: O.P., M.G.E., A.K.T., S.G., A.B.O., Data Collection or Processing: O.P., S.G., M.G.E., A.K.T., S.G., Analysis or Interpretation: O.P., A.K.T., M.G.E., S.G., A.B.O., A.H.E., S.G., Literature Search: A.K.T., S.G., A.B.O., Writing: O.P., A.K.T., M.G.E., S.G., A.B.O., A.H.E., S.G.

Conflict of Interest: No conflict of interest was declared by the authors.

Financial Disclosure: The authors declared that this study received no financial support.

\section{References}

1. Moll HA. Challenges in the validation of triage systems at emergency departments. J Clin Epidemiol 2010;63:384-388.

2. Travers DA, WIler $A E$, Bowling $J M$, et al. Five-level triage system more effective than three-level in tertiary emergency department. J Emerg Nurs 2002;28:395-400

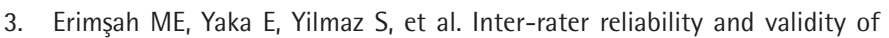
the Ministry of Health of Turkey's mandatory emergency triage instrument. Emerg Med Australas 2015;27:210-215.

4. Alquraini M, Awad E, Hijazi R. Reliability of Canadian Emergency Department Triage and Acuity Scale (CTAS) in Saudi Arabia. Int J Emerg Med 2015;8:80.

5. Cooper RJ, Schriger DL, Flaherty $\mathrm{HL}$, et al. Effect of vital signs on triage decisions. Ann Emerg Med 2002;39:223-232.

6. Durand AC, Gentile $S$, Gerbeaux $P$, et al. Be careful with triage in emergency departments: interobserver agreement on 1,578 patients in France. BMC Emerg Med 2011;11:19.
7. McHugh ML. Interrater reliability: the kappa statistic. Biochem Med (Zagreb) 2012;22:276-282.

8. Garbez $\mathrm{R}$, Carrieri-Kohlman $\mathrm{V}$, Stotts $\mathrm{N}$, et al. Factors influencing patient assignment to level 2 and level 3 within the 5-level ESI triage system. J Emerg Nurs 2011;37:526-532.

9. Baumann MR, Strout TD. Evaluation of the Emergency Severity Index (version 3) triage algorithm in pediatric patients. Acad Emerg Med 2005;12:219-224.

10. Olsson T, Terent A, Lind L. Rapid Emergency Medicine score: a new prognostic tool for in-hospital mortality in nonsurgical emergency department patients. J Intern Med 2004;255:579-587.

11. Widgren BR, Jourak M. Medical Emergency Triage and Treatment System (METTS): a new protocol in primary triage and secondary priority decision in emergency medicine. J Emerg Med 2011;40:623-628.

12. Brillman JC, Doezema D, Tandberg D, et al. Triage: limitations in predicting need for emergent care and hospital admission. Ann Emerg Med 1996;27:493-500.

13. Caterino JM, Holliman CJ, Kunselman AR. Underestimation of case severity by emergency department patients: implications for managed care. Am J Emerg Med 2000;18:254-256.

14. Farrohknia N, Castrén $M$, Ehrenberg A, et al. Emergency department triage scales and their components: a systematic review of the scientific evidence. Scand J Trauma Resusc Emerg Med 2011;19:42.

15. Read S, George S, Westlake $L$, et al. Piloting an evaluation of triage. Int J Nurs Stud 1992;29:275-288.

16. Gerdtz MF, Bucknall TK. Triage nurses' clinical decision making. An observational study of urgency assessment. J Adv Nurs 2001;35:550-561.

17. Goodacre S, Turner J, Nicholl J. Prediction of mortality among emergency medical admissions. Emerg Med J 2006;23:372-375.

18. George S, Read S, Westlake L, et al. Differences in priorities assigned to patients by triage nurses and by consultant physicians in accident and emergency departments. J Epidemiol Community Health 1993;47:312-315. 